\title{
Leadership Disruption: Time to Reimagine Leadership Talent
}

\author{
Dr. Linda Ellington \\ Professor of Business, Southern New Hampshire University, Manchester, USA \\ *Correspondence: Dr. Linda Ellington, 1.ellington@snhu.edu
}

ABSTRACT: Rapid changes in the global orbit, whether these are demographics, politics, pandemics or even technology shifts, all have considerable implications for leaders. The current world context is disrupting leadership practices because they are no longer meeting the needs of organizations and are forcing the reimagining of the talent needed to lead in this volatile era.

The purpose of this article is to first identify the major drivers of the disruption. Secondly, to examine leadership through Humanocracy termed by Hamel and Zanini [1]. Third, there is a conversation around being able to adapt to the speed of change through a process of hyper-learning, that transitions to hyper-leading [2,3]. Finally, as all great writing connects to theories, this article will include IQ, EQ, CQ, and LQ and their relevancy to leading through disruption.

Keywords: Leadership, Disruption, Humanocracy, Design thinking, Agile leading, Growth mindset, Innovative thinking, Hyper-Learning, Hyper-Leading

\section{ARTICLE INFORMATION}

Author(s): Dr. Linda Ellington

Received: 25 Feb, 2021; Accepted: 07 April, 2021; Published: 19 Apr, 2021 e-ISSN: 2347-4696;

Paper Id: BMN-IJBMR-2021-28;

Citation: doi.org/10.37391/IJBMR.090203

Webpage-link:

https://ijbmr.forexjournal.co.in/archive/volume-9/ijbmr-090203.html

\section{THE DISRUPTION}

The global turmoil, whether it is a pandemic of galactic size, a political upheaval, an economic crisis, or even a seismic shift in the technology, disruption is shifting the role of leadership as we know it. To reimagine how to lead in the disruptive landscape, there are four actions needed to incorporate into organizational conversations: reality, relevancy, rethinking, and reimagining. The shadow side of not paying attention to those four objectives causes leaders to fruitlessly waste time and money by focusing on superficial skills and abilities.

To illustrate the thinking behind the major drivers causing the disruption, one only needs to conjure up a dystopian version of reality. Literature describes the themes of a dystopian viewpoint of what might happen to the world: society rebellion, political oppression, revolutions, wars, and climate disasters [4]. Keep in mind that the opposite is utopia, which is not reality, yet many leaders still use that mindset to lead, which is irrelevant in today's global landscape.

The right leaders in this disruptive era will undoubtedly emerge and so the question is, what form will these leaders take? If we do this wisely, we can bet on two things. First, that leading will be directly relevant to the global drivers. Second, bet that the leaders will need to be realistic and responsive to the talent constraints in the organization. This will require them to deal with a threshold handicap they must overcome which is the inertia of 'it has always been thus' - a syndrome that too often fools leaders in any enterprise [4]. Now one might ask, how does a leader shrug off that syndrome to successfully lead through disruptive times? The simple answer is right in front of us; however, let us not use the utopia lens to see, but rather the realistic lens. Redefining what it means to lead on a global scale is constantly being redefined and is more acute than ever before [5]. The current world context is responsible for the dark side of such a global stage; growing inequality, unemployment, underemployment, and increased global mobility due to forced migration. Thus, these disruption challenges have created dynamic and complex changes that are introducing challenges for those who dare to lead $[2,6]$.

This will also challenge leaders to get their myopia corrected; meaning facing any disruptive issue with a broader view and broaden participation by others [4]. With this broader picture of leadership capacity, the visual expands to incorporate organizational diversity. The importance of this is to stop the stampede toward a single, homogeneous model of leadership. Iger [7] posited from his 15 years as CEO of the Walt Disney Company, that diversity is critical to the success of an organization, which means leaders must build a culture of trust based on the brilliance of diversity, fuel a deep and abiding curiosity throughout the organization, and always have the back of all employees when facing things that are difficult to face [7]. Iger stated:

When in a position of real leadership, be decent to people, treat everyone with fairness and empathy. This does not mean that you lower your expectations or convey the message that mistakes do not matter but rather it means you create an environment where people know you will hear them out, that you are emotionally consistent and fair-minded, and that they will be given second chances for honest mistakes [7].

In her book, Dare to Lead, Brown [6] challenged leaders to step up to the ideas of daring greatness through diversity, rising strong and braving the wild unknown, escalating into being change makers and culture shifters. One must lead with intentionality in reimaging and re-engineering their leadership 
practices and welcome the fact that people-centric organizations tend to come up with many different associations, as least of which are idiosyncratic and possibly unique which builds into the idea of humanocracy. Even as we look back into history, Tolle [8] told us that the mind gives form to the creative impulse or insight and even the greatest scientists have reported that creativity is a result of leaders and followers who do not know how to stop thinking.

\section{HUMANOCRACY}

In this age of disruption, top-down power structures and rulechoked systems are liabilities. They crush creativity and stifle initiative. Drawing on more than a decade of research, Hamel and Zanini [1] noted when leaders run out of patience with bureaucracy and if a leader wants to build an organization that can out-run change and is committed to giving every team member the chance to learn, grow and contribute, then the unstoppable movement to create an organization that is fit for the future and fit for human beings will be reality. Hardiman [8] noted that creativity is a hallmark of 21 st century people skills. Hardiman stated, "The brain processes information when people are engaged in creative tasks, as opposed to ordinary activities that depend on rote knowledge" [9].

According to Gardner [10] leaders should inspire creativity throughout the organization. However, like intelligence, the term creativity has been applied over the years as an honorific label to a wide range of individuals and situations. But as happened with the term intelligence, it is necessary to shift from the individual mind to the broader idea of distributed sociocultural bases of intelligence that then extends the nature of creativity where people tend to come up with many different associations in solving problems [11, 12]. Hamel and Zanini described this phenomenon as humanocracy [1]. One might explore future research that may be able to develop a theory, and thus identify leadership competencies of a humanocracy leader.

Through the practices of humanocracy, the time to dismantle bureaucracy effectively, passionately, and comprehensively is now; and how this is done is to reimagine leadership abilities that can revitalize organizations. Hamel and Zanini [1] issued a stirring call for leaders to do better - to build organizations that liberate the everyday genius of the people inside the organization. Be the leader who infuses the spirit of creativity and a growth mindset that inspires the future organization; be the leader who replaces chain of command with chain of trust and radical transparency; be the leader who unlocks gamechanging innovation [1, 13, 14]. Be the leader who can identify and achieve the right goals for the organizations and communities they serve. This is needed now more than ever, especially at the micro and macro levels of leadership.

Micro level is when workers are pressured by the move to a shared economy, the untethering of work from a physical location, the displacement of human labor by technology and growing demands for diversity, inclusion, and belonging [15]. As employment status shifts from gainful employment by a company to multiple independent and less secure worker modalities, employees are forced to change careers due to (in) voluntary disruptions or setbacks, constantly needing to recreate themselves, and build a greater resilience into their career journey.

Macro level is societal which is already strained and threatened by the global risk context. The strains are due to demographic pressures, fear of robotics and artificial intelligence supplanting many low and mid-tier jobs, the lingering impact of the global economic downturn, the mass migration of labor, the hollowing out of work, and growing income inequality [15].

Based on Claus [2] and Hess's [3] call for action a leader needs to turn dead end jobs into get-ahead jobs - which is possible if the leader treats every person and their respective role as indispensable to collective success.

Thus, the call to action is:

- Create a hyper learning environment: continuous learning, unlearning, and relearning at the speed of change [3].

- Humanize the workplace to optimize the power of human cognitive, emotional, and behavioral performance individually and organizationally [1].

- Create an environment to think differently knowing the key likes, making everyone in the organization feel differently that then fuels action by showing people potent reasons for change that spark their emotions [16].

- Foster intrapreneurial thinkers within the organization [17].

Make decisions in environments with lots of uncertainty and little data; and connect with other human beings through high emotional engagement and collaboration $[3,10]$.

The most important of all will be the ability to deal with change, learn new things, and preserve a mental balance in unfamiliar situations. Hess stated, "A symphony of synchronicity is, quite simply, beautiful. One cannot help but be impressed by what human beings can accomplish when they work in concert" [3].

\section{THE LEADERS' GAME}

To lead through the disruptions, leaders need to have the talent to play a game with interchangeable pieces. However, as Miller [13] noted a leader who cannot just keep jumping from activity to activity will continue to play checkers when the name of the game is chess. If one is playing checkers in a chess world, the leader will remain playing small and will not be a critical-shift thinker who can succeed.

Therefore, if a leader accepts the challenge to be the leader needed now, they must elevate their leadership game or at the minimum know which game is being played. Possibly we could state that leadership has always demanded the best, and maybe that has not changed, but something has - complexity is the primary culprit. Although, the title of Miller's book, Chess not Checkers, is a metaphor for leaders, it is much more 
than that [13]. He explained chess is a game that requires leaders to know that individual pieces have unique abilities that drive unique 'moves' to win [13]. This metaphor could be the blueprint for future leading and Dweck [14] agreed that the future game plan is for leaders to substitute their old way of thinking for a new mindset: a growth-mindset in the game of leading.

Miller identified four moves based on the game of chess that can 'elevate a leader's game' [13].

Move One: Bet on Leadership: Growing leaders grow organizations.

Your capacity to grow determines your capacity to lead.

Move Two: Act as One: Alignment multiplies impact.

You will never really act as one unless you master cascading communications.

Move Three: Win the Heart: Engagement energizes effort. Never underestimate the power of those on the front lines doing the work.

Move Four: Excel at Execution: Greatness hinges on execution.

To help your team improve execution, measure what matters.

Dweck reiterated Miller's gaming idea as she amplified that the strategic moves in chess should include a mindset concept that is beyond the individual, applying it to the cultures of groups and organizations. This growth-mindset theory and practice identified by Dweck [14] and Collins [18] bolsters leaders to become great chess players who:

- Are self-effacing people.

- Constantly asking questions.

- Able to confront the most brutal answers.

- Constantly trying to improve.

- Move with confidence that is grounded in facts, not built on fantasies about their talent

Speaking of game playing, Palus and Horth [19] noted that the ways leaders and their followers develop efficacy during change is to understand that chaos in organizations is not random and everyone needs to understand that playing the right game is essential to foster creativity and innovation. "Fundamental innovation and creativity come from serious play on the fringes of the organization." [19]. They identified three play activities that leaders can take:

- Constantly ask questions.

- Learn to seek the patterns for their own sake before trying to exploit them.

- Deliberately introduce a small, temporary number of disruptions and then observe how the old patterns shift and new one's form.

Be the leader who has the talent and courage to create an organization that is not brittle and not backward-looking. This type of leadership pessimistic view would be justified except for one salient fact:

As human beings we are resilient, inventive, and exuberant. The fact that organizations are not suggests that in some important ways, the organizations are less human than we are. Ironically, it seems that human-build organizations have scant room for exactly those things that make us furless bipeds special - things like courage, intuition, love, playfulness, and artistry [1].

It would behoove us to pay attention to a different way of viewing our organizations. Dweck [14], Collins [18], and Hess [3] told us to shift to a growth-mindset concept because that way of rethinking has the power to motivate those we lead, to transform organizations, and to inspire followers to want to follow us.

To proliferate the growth-mindset conversations we should examine the philosophies from the world's highest performing leaders and their extraordinary stories of being pioneering agents of change as identified in Rubenstein's book, How to Lead (2020). He identified and described 31 best-known leaders and how their leadership grew over the course of a life and career. Their stories reveal the value that a leader can bring to a challenge, often affecting humanity in profoundly positive ways which supports the research of Hess [3] relevant to humanocracy. Rubenstein not only shared each of the 31 leaders' principles and practices but was able to categorize the leaders as: visionaries, guilders, transformers, commanders, decision makers, and masters. Rubenstein stated, "I was always fascinated with leadership and specifically, what individual leaders can accomplish by the power of their intellect, level of their unique skill, force of their personality, or effectiveness of their ability to persuade" [3].

The edited work of Sowick [20], supported the notion that challenges of leadership are growing and not shrinking. It would benefit leaders to read Mack's chapter, Leadership in the Future in Sowick's edited book [21] in which he stated, "I will propose at the outset that the future of leadership is the future of humanity and when thinking about what is relevant in leadership, it is difficult not to respond, 'what is not?' [21].

\section{‡ 4. REIMAGINING THROUGH INNOVATIVE THINKING}

Leaders of the future must embrace imagination and innovating thinking (rethinking) as essential to both identification of emerging problems and crafting of workable solutions. Workable means "resources, including political will, are available for solution design and successful implementation in a global context" [20]. Heifetz [22] also stated that indeed there are no easy answers but leaders in the future must understand what is realistically happening in the profound transformation of new values, new connections, and new tools where many old approaches and resources are vanishing. 
Burn \& Houston's chapter, Social Artistry: A Whole System Approach to Sustainable Analysis and Leadership Practices [23], noted that it is not only imperative for leaders to think differently in the future, but also to incorporate additional leadership capacity that comes from social artistry. By that they mean the ability to connect by incorporating emotion and spirit, connecting to Hess's 2020 research of humanocracy. The call for social artistry comes from the realization that leaders must grasp reality in knowing there is a re-patterning of human nature to one of global citizenry, as well as the regenesis of society through changes in existing social structure, institutions, and governments. This social artistry contains a four-level system change in sensory-physical, psychologicalhistoric, mythic-symbolic, and integral-unitive methods of leading [23]. One might ask is social artistry mirroring the concept of design thinking.

\section{LEADERS AS DESIGN THINKERS}

According to Siang [24] design thinking is a non-linear, iterative process that teams use to understand users, challenge assumptions, redefine problems and create innovative solutions. It is about the principles of designing to the way people work [25]. This type of thinking uses mainly abductive reasoning - namely to conjecture what could possibly be true and 'actively look for data points, challenge accepted explanations and infer possible new worlds [26].

One of the hallmarks of design thinking is simplicity: reducing unnecessary workplace complexity, designing employee solutions that are compelling, enjoyable, and simple [27]. Craig [4] quoted John Ruskin, a Victorian artist who stated "It is far more difficult to be simple than to be complicated; far more difficult to sacrifice skill and easy execution in the proper place than to expand both indiscriminately" [4]. A design-centric concept focuses on the emotional experiences of organizational stewards (employees), creates models to examine complex problems in the workplace, uses prototypes to explore potential solutions, and tolerates failure. Thus, a new leadership talent is evolving centering on needed societal interventions, shared responsibility, and coordination at various levels - employees, employers, and the broader society.

One of the emerging talents is to be able to incorporate the agile leading component of the process for work to be done in team configuration that is network-based and flatter organizational structures leaving greater control over their work and empowerment to employees [4]. Agile methodologies are being applied to general management and yet have great multiple applications going up the leadership hierarchy of the organization [28]. Exemplars of some agile concepts and tools are project charter, personas, user stories, SCRUM teams, product backlog, sprints, stand-up meetings, and sprint retrospectives [29, 30].

By not being an agile leader, mistakes will stem from lack of clarity about the goals and objectives of the organizational vision and direction. Mistakes created from teams who have not been empowered the freedom to explore alternatives or from teams who have not been given enough time to choose thoughtfully from the alternatives they have invented or discovered is the failure of the leader who did not consider the ramifications of making changes. Thus, an important characteristic of an agile leader is one who moves from hyperlearning to hyper-leading.

\section{HYPER-LEARNING TO HYPER- LEADING}

There are a growing number of research findings from the neuro and cognitive sciences that can inform the learning to leading process [9]. She separates neuromyth from neuroscience by considering that neuromyths are not only incorrect in the transition from learning to leading, but also organizational employees are forced by policymakers to use methods that are not relevant to an unstable and chaotic world. To stay relevant throughout a disruptive time one must be able to excel cognitively, behaviorally, and emotionally in ways that technology cannot. To transition from a hyper-learner to a hyper-leader it is imperative to overcome the reflexive ways of seeking confirmation of what we believe, emotionally defending our beliefs and our ego, and seeking cohesiveness of our mental models [3,9]. "Although many of us may think of ourselves as thinking creatures that feel, biologically we are feeling creatures that think" [31].

Hess [3], Hardiman [9] and Dweck [14] agreed that changing our behaviors requires changing our way of being - our internal story of who we are and how the world works. Hess noted that before we can enable ourselves to become hyperlearners growing into hyper-leaders, we need to create the right mindset - a story of why we should change [14]. Dweck [14] supported this idea as documented her book, Mindset that the view that we adopt for ourselves profoundly affects the way one leads their life and leads others [14]. Thus, her philosophy called the growth-mindset, is based on the knowledge that the basic qualities of our thinking cultivate efforts, targeted strategies, and help from others. To illustrate the framework of a growth-mindset:

- Find challenges for you to grow.

- Seek experiences that will stretch you.

- Use the passion for stretching oneself and sticking to it, even when it is not going well [14].

Connecting to the cognitive aspect of hyper-leading, Hardiman noted that there is an intricate interplay between cognition and emotion. Burn \& Houston's chapter in edited book by Sowick, [23] supported Hardiman's theory as they noted that leadership capacity comes from social artistry; meaning the ability to connect by incorporating emotion and creativity. To expand on the work by Hardiman [9], Burn and Houston, both neuroscientists continued to demonstrate differences in how the brain processes information when humans are engaged in creative, spontaneous tasks, as opposed to activities that depend on rote knowledge. 
From their research and findings, they determined that leaders need to:

- Gain a new vision.

- Create a workplace environment for one to know "construction zone: brains in progress."

- Encourage everyone to do new things, not simply repeating what other generations have done.

- Foster ample opportunities to have everyone be inventive and to apply knowledge in ways that contribute to developing and fostering the creative / curious mind.

- Provide time that promotes divergent thinking thus allowing for new and distinct free-flowing thoughts.

We know that our capacity to lead is not fixed in stone at birth as everyone has high potential to grow. We all can learn to lead no matter what our IQ score is. Let that quotient not be our obstacle or excuse for not taking bold steps into being the leader who takes their organizations to higher heights moving through the global orbit.

\section{THE QUOTIENT THEORIES}

Theories that are widely known range from intelligence (IQ), emotions (EQ), curiosity (CQ) and a relatively new term that relates to leadership quotation (LQ). Most of us are familiar with IQ and EQ and the properties of CQ; however, recently there is a trend to expand quotient theories to include the concept of LQ, or the Leadership Quotient.

The oldest of the three Q theories mentioned above is the wellknown IQ. It measures cognitive ability and assigns a value. This value describes how one's measured intelligence falls within the range of the whole population. Meanwhile, EQ is often defined as emotional intelligence and is a measure of the level of ability to understand other people, what motivates them and how well one can work cooperatively with them. Businesses and other major organizations have begun to consider EQ in potential hires, particularly leaders. They claim that the EQ is a better predictor of executive success and the ability to develop business growth strategies than other measures, including IQ.

One might say it is a new neighborhood in which LQ moved into. LQ has joined the quotient theoretical research and a wide variety of researchers, authors and organizations have developed ways to measure LQ. According to Murphy [32] Steven Covey's Leadership Quotient is the most popular. His is a measure of ability against the four main imperatives of leadership: develop trust, clarify purpose, align systems, and unleash talent. One might ponder why the leadership quotient works, especially on the global scale. It works because it is a loud wake-up call for any leader who is still trying to apply old leadership paradigms to today's workforce. In addition to individual empowerment being a driving force behind the reengineering of their skills and talents, cultural diversity has forever changed the world of work. Appreciating the impact that the quotient leadership has on increasing organizational profits, this style of leader understands how to motivate employees without invoking hierarchal authority. The global quotient leaders flatten their immediate playing field, their employees gain the security and freedom to contribute beyond the status quo, which in turns heats up creativity, productivity, and profits [33].

Simply put, Snyder uses the analogy through a story:

Increasing access to specialized knowledge about our organizations transforms the way employees feel about their organizational leaders. Knowledge serves as the lens through which we view the world. It is like watching a baseball game from the announcer's booth versus the dugout. From the announcer's booth we have a seat with the power to change both our comprehension and convictions about the game. Why? Because from this zoomed-out vantage point we gain new specialized knowledge about what is really occurring on the field - knowledge we never would possess from the depressed elevation of the dugout [33].

\section{CONCLUSION}

In characterizing an era with a specific label, one runs the risk of making a claim that cannot be substantiated. And yet, the leadership disruption label fits clearly in the 21 st century as the global planet seems to be under a strong magnetic force of uncertainty and chaos. Leading through disruption presents a unique set of opportunities and challenges for leaders to not only reinvent themselves but to reimagine their organizations. Leaders will need a distinct set of skills to lead successfully through the disruption: act decisively, never panic, communicate clear directions to the teams, solve problems creatively, and achieve the results to be the most thorough transformation [4]. Adding to the label disruptive leadership, Palus and Horth [19] contend that the words volatile, multidimensional, and unprecedented are key descriptors when leading through challenges.

An overarching aim of this article has been to demonstrate that the study of disruptive leadership can inform as well as be informed by the research on the phenomena of global shifts due to disruption and its relationship in the sciences of the mind. The certainty for leaders is that the future will hold yet more disruptions. And yet, the annoyance of disruptions provides a fascinating window of how leadership will change organizations.

The article hopefully inspires readers to develop new and relevant practices in the field of disruptive leadership studies. Raelin [12] described this field as "leadership-as-practice" movement. The essence of the practice is a coordinative effort among people, whether leaders or followers, who choose through their own rules to achieve a distinctive outcome. It also tends to encompass creative problem-solving that are shared within a community. We live in a world of accelerating change, where the future is less and less an extrapolation of the past. Change is unrelenting, pitiless, and occasionally shocking. As Hamel \& Zanini told us, "Welcome to the age of upheaval" [1]. 


\section{Business and Management Research (IJBMR)}

Review Article | Volume 9, Issue 2 | Pages 118-123 | e-ISSN: 2347-4696

\section{REFERENCES}

[1] Hamel, G., \& Zanini, M. (2020) Humanocracy. Boston, USA: Harvard Busines School Publishing.

[2] Claus, L. (2019) HR disruption-Time already to reinvent talent management. BRQ Business Research Quarterly 22: 207-215.

[3] Hess, E.D. (2020) Hyper-Learning: How to Adapt to the Speed of Change. Oakland, USA: Berrett-Koehler Publishers.

[4] Craig, R. (2015) College Disrupted. New York, USA: Palgrave MacMillan Trade.

[5] Freska, A., Claus, L. (2013) The new global context: is the world really flat? Global HR Practitioner Handbook 1: 5-15.

[6] Brown, B. (2018) Dare to Lead. New York, USA: Random House.

[7] Iger, R. (2019) The Ride of a Lifetime: Lessons learned as CEO of the Walt Disney Company. New York, USA: Random House.

[8] Tolle, E. (1997) The Power of Now. Vancouver, Canada: Namaste Publishing.

[9] Hardiman, M. (2012) Brain-Targeted Teaching Model. Thousand Oaks, USA: Corwin Publishing.

[10] Gardner, H. (1993) Creating Minds. New York, USA: Perseus Books.

[11] Herman, D. (2013) Storytelling and the Sciences of Mind. Cambridge, USA: The MIT Press.

[12] Raelin, J.A. (2016) Leadership-as-Practice. New York, USA: Routledge Publishing.

[13] Miller, M. (2015) Chess not Checkers: Elevate your Leadership Game. Oakland, USA: Berrett-Koehler Publishers.

[14] Dweck, C.S. (2016) Mindset: The New Psychology of Success. New York, USA: Random House.

[15] The Global Risk Report 2017 (2017) World Economic Forum Risk Perception surveys, 2016.

[16] Kotter, J.P. (2002) The Heart of Change. Boston, USA: Harvard Business School Publishing.

[17] Smith, L. (2003) Leadership: The Intrapreneurial experience at the University of Oxford and the University of Warwick, United Kingdom. Doctorate Dissertation, Florida Atlantic University, Boca Raton, Florida.

[18] Collins, J. (2001) Good to Great: Why Some Companies Make the Leap and Others Don't. New York, USA: HarperCollins.
[19] Palus, C.J., \& Horth, D.M. (2002) The Leader's Edge. San Francisco, USA: Jossey-Bass.

[20] Sowcik, M. (2015) Leadership 2050. Bingley, UK: Emerald Group Publishing.

[21] Mack, T.C. (2015) Leadership in the Future. In: Sowick, M. (Ed.), Leadership 2050. Bingley, UK: Emerald Group Publishing. pp. 9-22.

[22] Heifetz, R. (1998) Leadership without easy answers. Boston, USA: Harvard University Press.

[23] Burn, S., \& Houston, J. (2015) Social Artistry: A Whole System Approach to Sustainable Analysis and Leadership Practices. In: Sowick, M. (Ed.), Leadership 2050. Bingley, UK. Emerald Group Publishing. pp. 225-240.

[24] Siang, T.Y. (n.d.) What is Design Thinking? Interaction Design Foundation.

[25] Kolko, J. (2015) Design thinking coming of age: the approach once used primarily in product design, is now infusing corporate culture. Harvard Bus. Rev. 93(9): 66-69.

[26] Martin, R. (2009) The Design of Business: Why Design Thinking is the Next Competitive Advantage. Boston, USA: Harvard Business Review Press.

[27] Bersin, J., Solow, M., Wakefield, N. (2016) Design Thinking: Crafting the Employee Experience.

[28] Rigby, D.K., Sutherland, J., Takeuchi, H. (2016) Embracing agile: how to master the process that is transforming management. Harvard Bus. Rev. 94(5): 41-50.

[29] Rose, D. (2015) Leading Agile Teams. In: Rubenstein, D.M. (Ed.), How to Lead. New York, USA: Simon \& Schuster.

[30] Canty, D. (2015) Agile for Project Managers. Salt Lake City, Utah: Auerbach Publications.

[31] Taylor, J.B. (2008) My stroke of insight: A brain scientist's personal journey. New York, USA: Viking Penguin.

[32] Murphy, T. (2014) Leadership Quotient by Design.

[33] Snyder, K. (2013) Why G quotient leadership works. In: Grogan. M (Ed.), The Jossey-Bass Reader on Educational Leadership. San Francisco, USA: John Wiley \& Sons. pp. 131147.

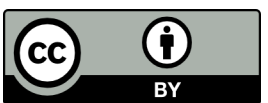

(C) 2021 by the Dr. Linda Ellington. Submitted for possible open access publication under the terms and conditions of the Creative Commons Attribution (CC $\quad$ BY) license (http://creativecommons.org/licenses/by/4.0/). 